\title{
Integrated slope stability assessment in a complex geotechnical and hydrogeological setting
}

\author{
R. Campbell SRK Consulting (UK) Ltd, UK \\ D. Mackie SRK Consulting (Canada) Inc., Canada
}

W.S. Anderson Teck Resources Ltd., Canada

\begin{abstract}
Integration between geotechnical and hydrogeological groups for slope stability studies is often discussed but more rarely appropriately implemented. Although guidelines exist, experience has shown that the communication and technical integration between the geotechnical and hydrogeological teams can be problematic. This paper presents an example of a holistic integration process which builds on established best practice guidelines rather than attempting to re-invent the currently accepted methodology. The Galore Creek copper-gold project, located in northwestern British Columbia, has been chosen as an illustrative case study.

The Galore Creek copper-gold deposit, owned by the Galore Creek Mining Corporation (GCMC), currently includes plans for three open pits and additional mining-related infrastructure. The proposed mining area is surrounded by high, rugged, and ice-capped mountains on three sides with the Galore Valley opening to the north. The area experiences high levels of precipitation (rainfall and snow), as well as a significant annual freshet period. Combined with challenging topographic and climactic conditions, pit wall stability will be influenced by a structurally complex, variable rock mass, and locally elevated and compartmentalised pore water pressures.

From the project outset, it was determined that an integrated approach to slope design would be required to consider the prevailing physical and environmental factors at play in the Galore Valley. To achieve the slope design in a practical and timely manner, both consultant and client geotechnical and hydrogeological teams met regularly from the initial planning and investigation stage through to the final stability modelling of the proposed pit slopes.

With targeted field investigations providing the framework to update rock mass, structure, and hydrogeological characterisation, a number of potentially unstable zones within the mining area were highlighted. Elevated pore water pressures, combined with a locally weak rock mass and significant slope heights (in excess of 1,000 metres), required constant interaction between the geotechnical and hydrogeological groups to ensure that appropriate inputs and material behaviour were represented within the numerical stability models. A number of pore water pressure scenarios were evaluated including average freshet and full dewatering system failure. These varied pore water pressure scenarios were assessed and exported as $2 D$ sections for limit equilibrium and finite element slope stability modelling.

With the project schedule in mind, the hydrogeological and geotechnical teams were required to constantly exchange ideas and information since slope geometry had to remain flexible due to the evolving pit designs. Regeneration of pore pressure grids, for input into numerical stability models was not practical due to time constraints during this period. Phreatic surfaces were used to reasonably approximate the hydrogeological conditions, providing an efficient, hydrogeologically-sound approach for use in the frequent slope stability modelling iterations. Once stable phreatic-based designs were achieved, the hydrogeological team then developed pore pressure grids for selected pit wall sections. In most cases, the applied pore pressure grids produced comparable stability behaviour when compared to the approximated phreatic surfaces. By approximating the phreatic surface for individual slope models, the time consuming requirement of re-modelling the hydrogeological condition for each design iteration was avoided.
\end{abstract}


The benefits realised through increased modelling efficiency represents a significant lesson taken from the Galore Creek integration exercise. Additionally, having both teams working in parallel, communicating inputs and results, design opportunities were realised due to a better understanding of the groundwater flow system and sensitivity of slope stability. Taking this integrated approach also reduced project delays and budget overruns related to excessive iterations between programs and groups.

\section{$1 \quad$ Introduction}

For slope stability studies, integration between geotechnical and hydrogeological groups can often be 'out-of-sync', conflicting, or simply missing significant physical components (e.g. proper structural model). In order to combat such disconnects, team members must have a mutual understanding of each other's needs and limitations. Experience has shown that a poorly integrated approach can rapidly exhaust study budgets, miss deliverable dates, and damage client-consultant relationships.

Although there are guidelines that exist for these disciplines (e.g. Read and Stacey, 2009; Sullivan, 2007), experience has shown that the communication and technical integration between the geotechnical and hydrogeological teams can be problematic. This paper presents an example of a holistic integration process which builds on established best practice guidelines rather than attempting to re-invent the currently accepted methodology.

The selection of mechanical and hydrogeological parameters and the selection of modelling tools form only a portion of the stability modelling process. Linking of the various technical disciplines should be initiated at the scoping level and refined through final mine design and, ultimately, operations. Best practice involves both geotechnical and hydrogeological teams working in conjunction and engaging in constant communication, while fulfilling their individual scope of work. Client awareness regarding the need for this link is critical.

The Galore Creek Cu-Au Project, owned by the Galore Creek Mining Company (GCMC), has been chosen as a demonstrative case study since complex topographical, climatological, geological and hydrogeological conditions all factor into slope stability analysis. At Galore Creek, these factors form a blend of technical problems which can only be addressed through systematic and transparent interaction between the hydrogeological and geotechnical groups. The applied process has avoided the most common study pitfalls where pore pressure and rock mechanics inter-relate to define slope stability.

This paper is written for consultants and clients with a focus on practical project execution within budget and scheduled timelines. The provided pre-feasibility level case study illustrates an example of 'good integration' where an integrated process was applied to a 'wet' pit. Fully coupled, 3D hydromechanical modelling was not considered to be required, rather, this example is based on a semi-coupled, 2D stability modelling, which in our experience, is often sufficient for hard rock open pit designs.

\section{$2 \quad$ Understanding the integration issue}

While the disciplines of geotechnics and hydrogeology are fundamentally dissimilar practices, both groups have one shared aim, which is to understand the mechanisms that control slope stability. Geotechnical groups focus on the collection of static data where risks and uncertainties relate to measured parameters that are handled deterministically or probabilistically. Hydrogeologists work with static data, but in many cases also deal with transient data (e.g. variation in water table, influence of periodic precipitation events, etc.). Data can be combined for simulations, but the hydrogeologist must also understand what water conditions to simulate, what controls or defines those scenarios and what is necessary to achieve the design objectives. Scenarios representing different conditions are often the output of conventional groundwater models, which typically have to consider a larger area than just the open pit (i.e. reflect regional boundary conditions). The differences in how the two disciplines address their respective components are important to consider when planning a project. 
Experience has shown that the most common pitfalls regarding the integration of geotechnics and hydrogeology for the assessments of slope stability are found to include:

- Schedule: Studies often run in parallel and are constrained by tight timelines. There is often a need to integrate a number of disciplines at short notice. Completed structural, lithological and hydrogeological models are rarely available when required. Therefore, certain parameters must be assumed to advance the geotechnical and hydrogeological workflows and experience must be relied upon to ensure these assumptions are not outside practical boundaries. Construction of groundwater models must be scheduled to start early in order to provide results in a timeframe that fits with the timing of the stability assessment, particularly if the groundwater models incorporate complexity that will be difficult to calibrate or solve numerically.

- Data Gathering: Geotechnical investigations typically focus on defining rock mass and structural characteristics within and directly adjacent to pit slopes. Alternatively, hydrogeological investigations often need to include or focus on peripheral aspects of the deposit that define groundwater and surface water conditions. Given these differing requirements, the format, location and scale of collected data can vary significantly. If investigation targets are not chosen properly or the hydrogeological program is forced to 'piggy back' on the geotechnical study, key parameters may be 'over-averaged' (e.g. excessively coarse domains), missed completely (e.g. major structures outside pit boundary), or over-parameterised (e.g. excessively fine fracture network).

- Geotechnical domains equal to hydrogeological domains: If hydrogeologists lack sufficient characterisation data, or if schedules and/or budgets are not available to complete a proper hydrogeological study, geotechnical domains are often assumed to be equivalent to hydrogeological domains. This assumption is either often not valid or the differences may not be fully considered. Such practice can lead to incorrect assumptions for hydrogeologic conditions.

- Software driven approach: Complications can arise if software is permitted to dictate the analysis methodology. Although recognised as an underappreciated modelling aspect (Sullivan, 2007), the time and effort required to use fully coupled hydromechanical solvers (e.g. FLAC3D (Itasca, 2013)) is sometimes neither justified nor necessary. Justifiable, relatively simple assumptions can often replicate more complex problems through semi-coupled modelling (e.g. application of 'snapshot' transient pore pressure grids or approximated phreatic surfaces to finite element (e.g. Phase ${ }^{2}$ (Rocscience Inc., 2013a)) or limit equilibrium (e.g. SLIDE models (Rocscience, 2013b)). Determination of an appropriate method is best defined as early as possible, before either discipline advances too deeply into analyses and modelling.

- Blasting and unloading: Blasting and unloading (i.e. destressing) must be considered and incorporated into both geotechnical and hydrogeological models. This is a potentially vital consideration for both technical teams, especially for larger slopes ( $>500 \mathrm{~m}$ height) where stability models are typically sensitive to pore pressures. If a blast damage zone is to be allocated to the geotechnical model, modified $\mathrm{K}$ or pore pressures values should also be similarly applied. 


\section{$3 \quad$ Integrated approach}

Figure 1 summarises a 'top down' decision making process that has been implemented recently for several pre-feasibility and feasibility studies. At the core of the process is the constant communication between geotechnical and hydrogeological teams; beginning at the proposal stage and moving through data collection, analyses, design, modelling and final reporting. Such communication serves to identify 'what is important' and guide the approach used for both modelling efforts.

From the proposal and planning discussions, questions regarding the rock mass, structure and hydrogeological setting can be asked and information gathered at least to a conceptual level. Even with an early stage greenfield project, a client's technical staff are able to provide sufficient feedback for the deposits physical characteristics to be defined. From these discussions, the geotechnical and hydrogeological teams must establish a scope of work to address data gaps and focus on critical issues to slope stability. At this stage, a plan for field investigations can be established and early decisions made on whether to use relatively simplistic semi-coupled or fully coupled methods.

At the outset of the analytical phase, it is useful to conduct high level non-coupled stability modelling with varying groundwater conditions in order to test slope sensitivity relative to pore pressure. As 3D geological and structural models are developed at the pre-feasibility or feasibility level, these initial trials can also be used to adjust the ongoing field investigation to target areas of concern. The period following early sensitivity analyses is one where hydrogeology and geotechnics typically diverge into independent workflows. Early development of the hydrogeologic conceptual model focuses on determining what the groundwater system is in the area of interest. These include, for example, understanding the site water balance, recharge processes and hydrogeologic boundary conditions, assessing controls on pore pressure with depth and water level variation over time.

As the geotechnical and hydrogeological workflows advance (as per Figure 1), the teams have a responsibility to communicate their analysis results periodically and discuss how these results may impact each other. It is often found that a later discovery can alter the framework of the conceptual models resulting in unplanned re-analysis.

As groundwater modellers start to look at mining scenarios, dewatering needs, etc., ongoing evaluations continue to be driven by the hydrogeological conceptual model and the fundamental understanding of the groundwater system. Similarly, the geotechnical team will finalise the geotechnical model, define material properties for each domain, and evaluate slope stability limitations through the kinematic analyses. At this stage, slope geometries based on preliminary phreatic surfaces and finalised rock mass and kinematic constraints are made available to the hydrogeological team.

As the independent geotechnical and hydrogeological workflows approach completion, the teams come together more frequently to finalise the locations and extent of required stability models. Final pore pressure scenario(s) are also made available along with coupling recommendations (i.e. direct versus indirect) and model outputs (i.e. final phreatic surface, steady state or transient finite element grid, or transient). With these components in hand, applicable software is selected and stability modelling is conducted leading to final design recommendations. 


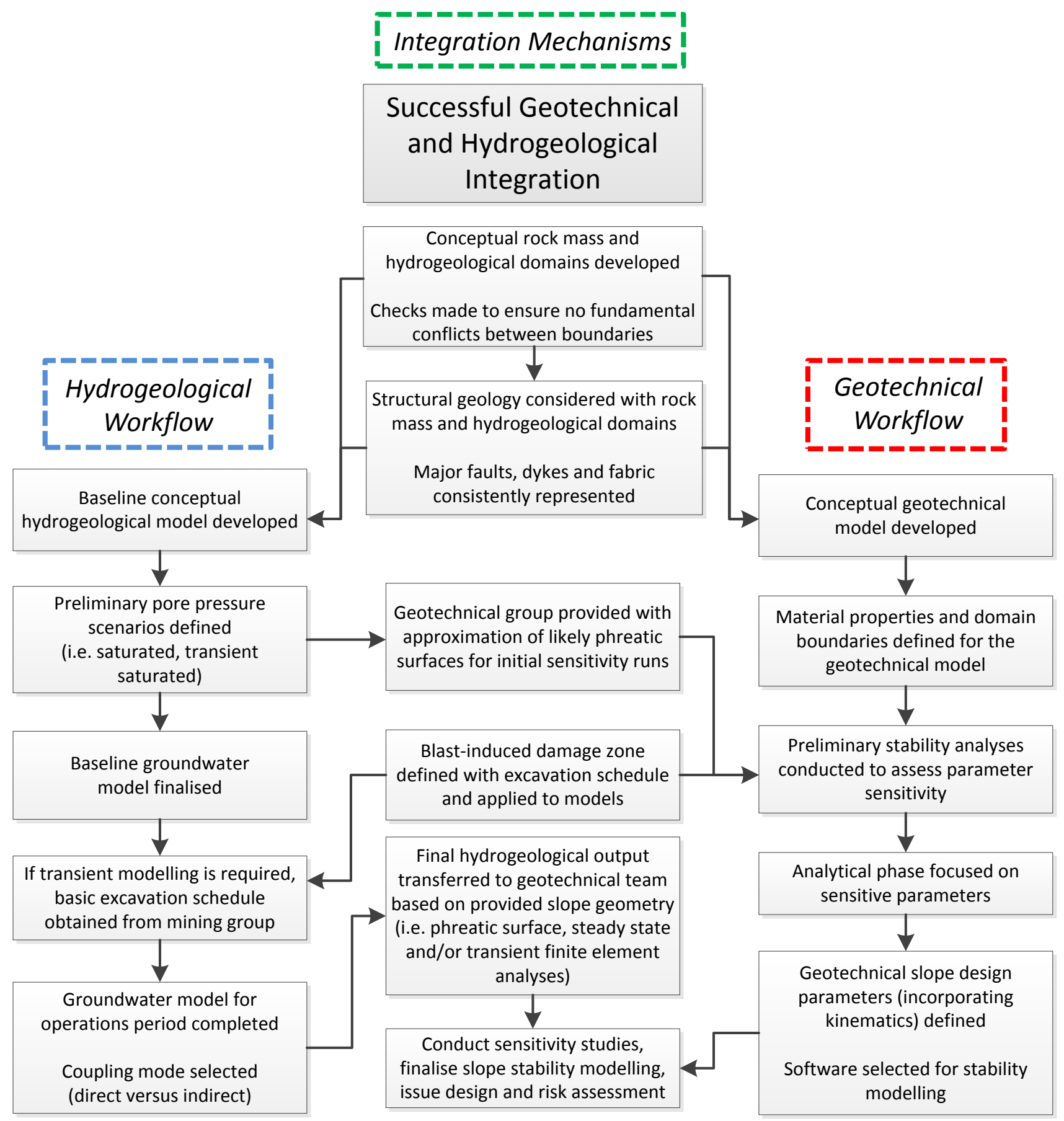

Figure 1 Geotechnical-hydrogeological integration process for Galore Creek

\section{$4 \quad$ Galore Creek case study}

The proposed mining area at the Galore Creek site is surrounded by high, rugged, and ice-capped mountains on three sides with the Galore Valley opening to the north (Figure 2). The area experiences high levels of precipitation, as well as a significant annual freshet (i.e. snowmelt) period. Combined with challenging topographic and climactic conditions, pit wall stability will be influenced by a variable rock mass, complex structure, and locally elevated and compartmentalised induced pore water pressures. 


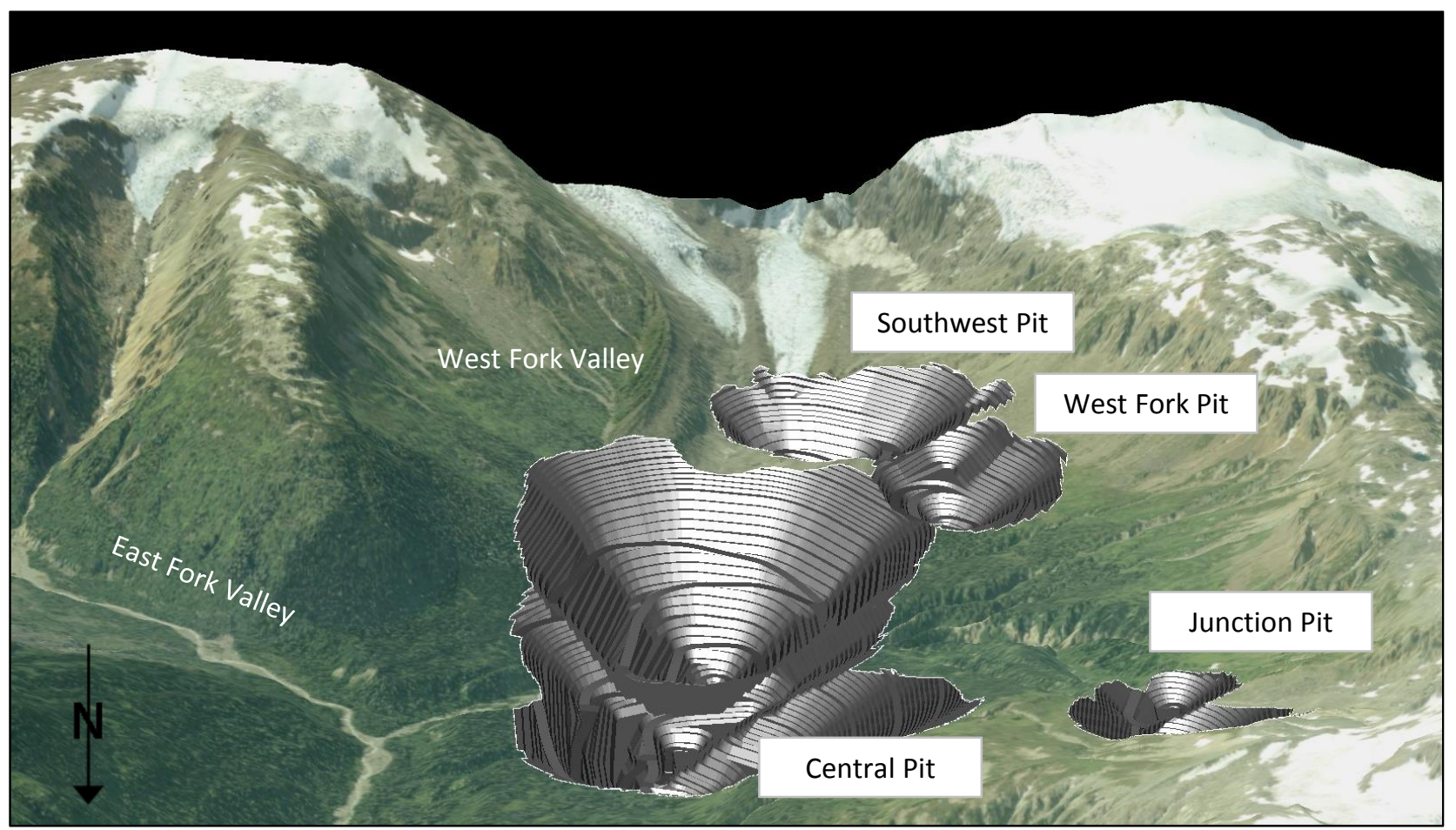

\section{Figure 2 Isometric view of the proposed prefeasibility-level open pits set within the Galore Valley}

The resource complex forming the study area is approximately $5 \mathrm{~km}$ long and $2 \mathrm{~km}$ wide. Drilling and mapping work completed by GCMC indicates the predominant rock units are volcanics and intrusives with some breccia units and late mafic dykes. Minor sedimentary rocks are identified at the northern end of the deposit.

Historical and recent geotechnical and hydrogeological work have been conducted on the property and provides a substantial database of information. Previous studies had highlighted weaknesses related to geotechnical and hydrogeological integration; particularly the groundwater model as related to structure and rock mass variability.

Although the geotechnical and hydrogeological characterisation initially focused on hydro-mechanically differentiating between the major lithological units (not including dykes and overburden), hydrogeological properties were found to be driven by structure, weathering and alteration, rather than lithology.

The stress state for this greenfield site has been based on the world stress map and information gained through other operations in northern British Columbia.

\subsection{Geotechnical context}

Five rock mass domains have been defined for the Galore Creek open pits. Overburden is also present but not significant in terms of overall slope design. Figure 3 illustrates the typical spatial arrangement of the major rock mock mass domains while Table 1 lists the parameters used for numerical modelling. 


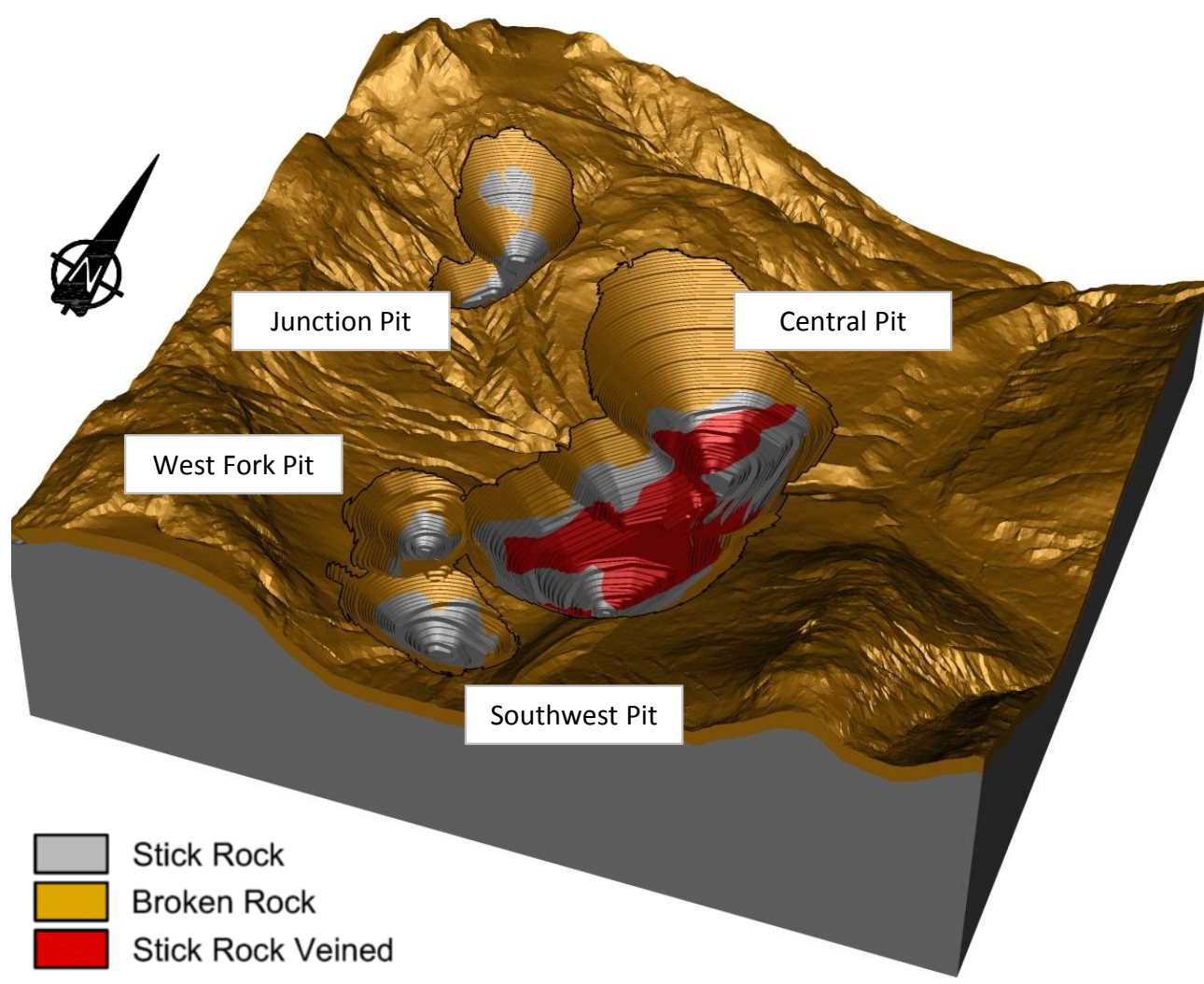

Figure 3 Modelled Galore Creek rock mass domains (structures and dykes not shown)

Table 1 Defined mechanical properties of Galore Creek rock mass domains

\begin{tabular}{|c|c|c|c|c|c|c|c|c|}
\hline \multirow{2}{*}{$\begin{array}{l}\text { Rock Mass } \\
\text { Domain }\end{array}$} & \multicolumn{2}{|c|}{$\sigma_{\mathrm{ci}}(\mathrm{MPa})$} & \multirow{2}{*}{$\begin{array}{c}E_{i} \\
(\mathrm{GPa})\end{array}$} & \multirow{2}{*}{$\begin{array}{c}\text { Poisson's } \\
\text { Ratio }\end{array}$} & \multirow{2}{*}{$\begin{array}{c}\text { Unit } \\
\text { Weight } \\
\left(\mathrm{MN} / \mathrm{m}^{3}\right)\end{array}$} & \multicolumn{2}{|r|}{ GSI } & \multirow{2}{*}{$\begin{array}{c}m i \\
\text { Mean }\end{array}$} \\
\hline & Mean & $\begin{array}{l}\text { Standard } \\
\text { Deviation }\end{array}$ & & & & Mean & $\begin{array}{l}\text { Standard } \\
\text { Deviation }\end{array}$ & \\
\hline Broken Rock & 50 & 15 & 15 & 0.30 & 0.026 & 37 & 8 & 19 \\
\hline Stick Rock & 100 & 20 & 40 & 0.22 & 0.028 & 60 & 10 & 24 \\
\hline Stick Rock veined & 75 & 15 & 36 & 0.26 & 0.028 & 60 & 10 & 19 \\
\hline Major structures & 20 & 5 & 4 & 0.40 & 0.024 & 20 & 3 & 10 \\
\hline Dykes & 70 & 15 & 16 & 0.22 & 0.026 & 50 & 8 & 19 \\
\hline
\end{tabular}

Broken Rock: The Broken Rock domain comprises near surface bedrock which has reportedly been modified by the transformation of anhydrite to gypsum and the subsequent dissolution of gypsum (Allen, 1971). The process has yielded a highly fractured and anisotropic rock mass with preferential sub-horizontal fracturing (Figure 4). Where major structures exist, the Broken Rock contact is often depressed relative to background values. It is believed that structures have locally acted as pathways for meteoric water infiltration thus allowing gypsum dissolution to extend to relatively greater depth.

A 3D wireframe of the Broken Rock contact with the underlying Stick Rock has been generated by isosurfacing drillhole and mapping data. Beyond the pit shells, where data are limited, the Broken Rock contact was projected to continue at a fixed depth beneath the topography. The Broken Rock basal contact ranges from 20 to $>150 \mathrm{~m}$ below ground surface. 
Stick Rock and Stick Rock Veined: Although lithological variability does exist within the Stick Rock (e.g. volcanics, intrusives, and breccias), detailed parametric studies and core photograph reviews suggest rock mass variability within lithology is not considered significant enough to warrant partitioning. However, an internal division of the Stick Rock domain was completed based on a zone of elevated anhydrite veining intensity which is characterised by slightly reduced intact rock strength. A three dimensional wireframe of the Stick Rock Veined domain has been generated from visual estimates of anhydrite (percent) taken during resource core logging.
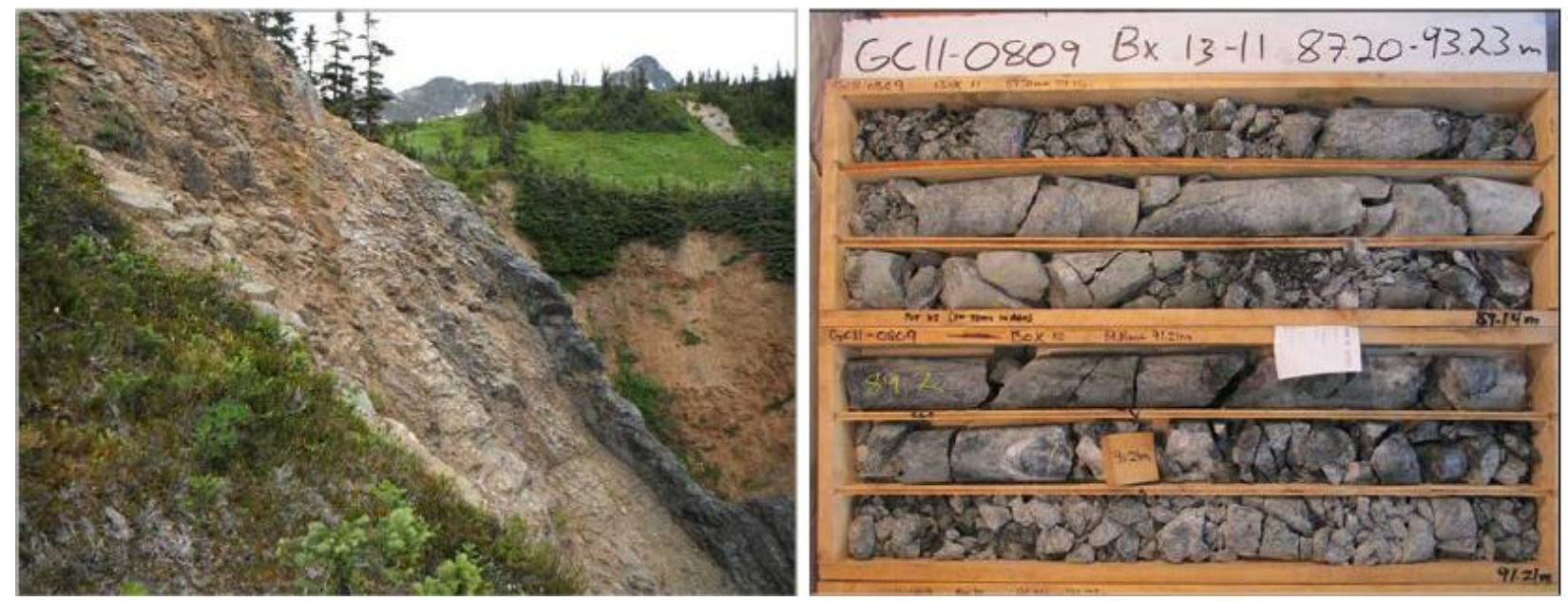

Figure 4 Outcrop and core box images of the Broken Rock domain

Major structures and dykes: major structures and dykes are common and highly relevant for the slope stability at Galore Creek. Features are clearly visible in both outcrop and air photo/remote sensing (i.e. displaced watercourses). A structural matrix has been created for each of the modelled faults and dykes in the project area. The matrix contains detailed information related to geometry, persistence, composition and feature confidence for each of the model faults and late dykes. Examples of typical major structure and dyke intersections are provided in Figure 5.

\subsection{Hydrogeological context}

The groundwater conceptual model was built using historical analyses and results from recent field investigations to constrain pore pressure distributions and water management requirements for slope stability models. The conceptual model was extended to the hydrogeological boundaries and tested using a 3D numerical model run in both steady-state and transient conditions. The model was then calibrated to observed groundwater level and creek baseflow information, providing a higher level of confidence in model results than previous studies.

In the Galore Creek case, hydrogeological domains essentially conform to the rock mass domains, except for a vertical segregation in the Stick Rock domain. The Stick Rock Veined rock mass domain is not influential from a hydrogeological perspective ( $K$ was not particularly sensitive to these features). The hydrogeological domains and associated parameters defined for the Galore Creek project are presented in Table 2. 

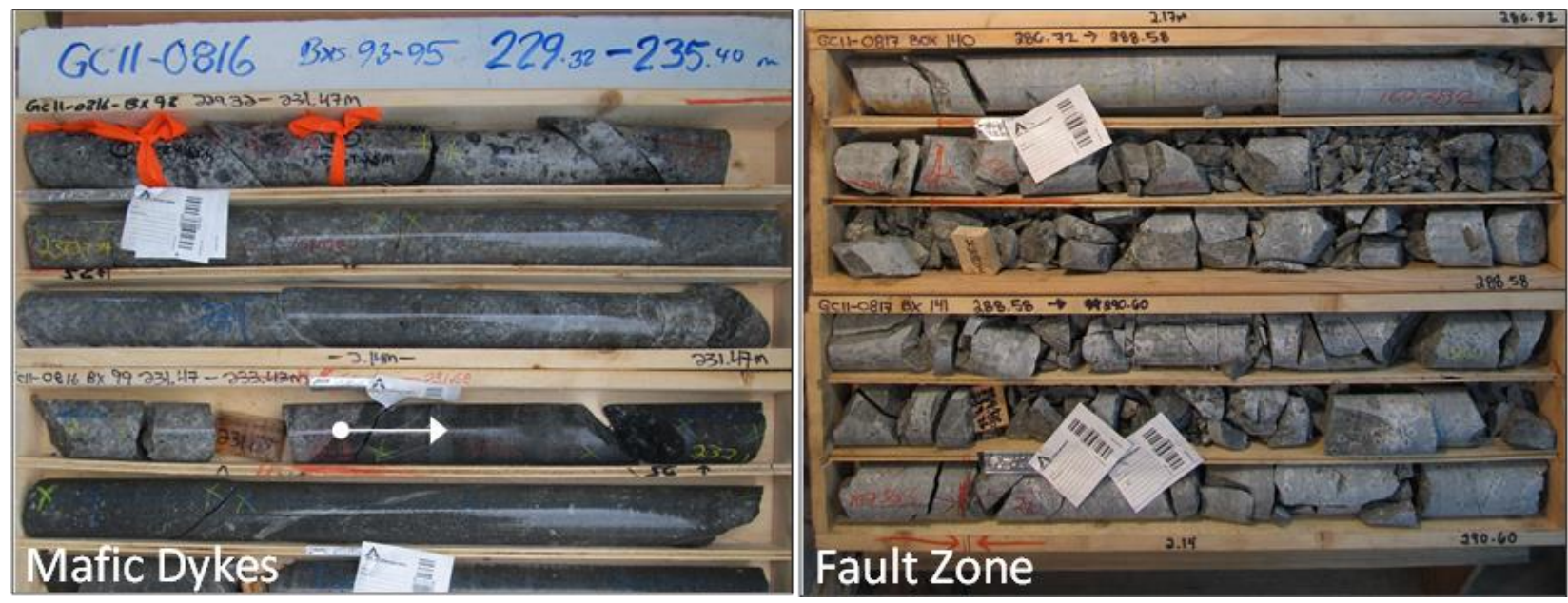

Figure 5 Examples of dykes and major structure intersections

Table 2 Defined hydrogeological properties of Galore Creek rock mass domains

\begin{tabular}{|c|c|c|c|c|}
\hline $\begin{array}{l}\text { Hydrogeological } \\
\text { Domain }\end{array}$ & $K(\mathrm{~m} / \mathrm{s})$ & $\begin{array}{l}\text { Specific } \\
\text { Yield }\end{array}$ & $\begin{array}{l}\text { Specific } \\
\text { Storage } \\
(1 / \mathrm{m})\end{array}$ & Description \\
\hline Overburden & $\begin{array}{l}2 \times 10^{-7} \text { to } \\
2 \times 10^{-6}\end{array}$ & 0.15 & $1 \times 10^{-4}$ & $\begin{array}{l}\text { Dominantly acts as an aquitard. No significant } \\
\text { overburden aquifer exists, although saturated } \\
\text { permeable lenses may occur. }\end{array}$ \\
\hline Broken rock & $\begin{array}{l}2 \times 10^{-6} \text { to } \\
1 \times 10^{-5}\end{array}$ & 0.01 & $1 \times 10^{-4}$ & $\begin{array}{l}\text { High fracture frequency; permeable bedrock. } \\
\text { Permeability enhanced through gypsum } \\
\text { dissolution. }\end{array}$ \\
\hline Upper stick rock & $7 \times 10^{-9}$ & 0.001 & $5 \times 10^{-6}$ & $\begin{array}{l}\text { Estimated to extend } 70 \mathrm{~m} \text { below Broken Rock } \\
\text { contact; represents a transitional hydrogeologic } \\
\text { zone between Lower Stick Rock and Broken } \\
\text { Rock. }\end{array}$ \\
\hline Lower stick rock & $1 \times 10^{-10}$ & 0.0001 & $1 \times 10^{-6}$ & $\begin{array}{l}\text { Extends from base of upper Stick Rock to depth. } \\
\text { Low fracture frequency and, on average, very } \\
\text { low K. }\end{array}$ \\
\hline Major structures & $6 \times 10^{-11}$ & 0.01 & $1 \times 10^{-4}$ & Faults assumed to be barriers. \\
\hline
\end{tabular}

Data suggest that faults can have high or low conductivity. The confidence in fault conductivity is low as a result of the inability to accurately constrain hydraulic testing zones in a single drill hole within the faults, which may be on the order of tens of centimetres wide. Single hole testing likely incorporated rocks on either side of faults, such that the permeability values obtained did not necessarily equate to the fault itself. Figure 6 depicts hydraulic conductivity for single hole fault tests.

Some faults (e.g. NW 6) show both high and low K zones, while others fall only in one cluster (often with variability). A consistent relationship between $\mathrm{K}$ and the nature of the structure could not be identified; it is not possible to predict a priori whether a fault will act as a barrier or a conduit, or if the data can be assumed to illustrate a fault core, damage zone or combination. From a stability perspective, barriers to flow can be problematic if the faults sustain high pore pressures in close proximity to pit walls. Conduits can also be problematic and act as recharge conduits to sensitive areas. 


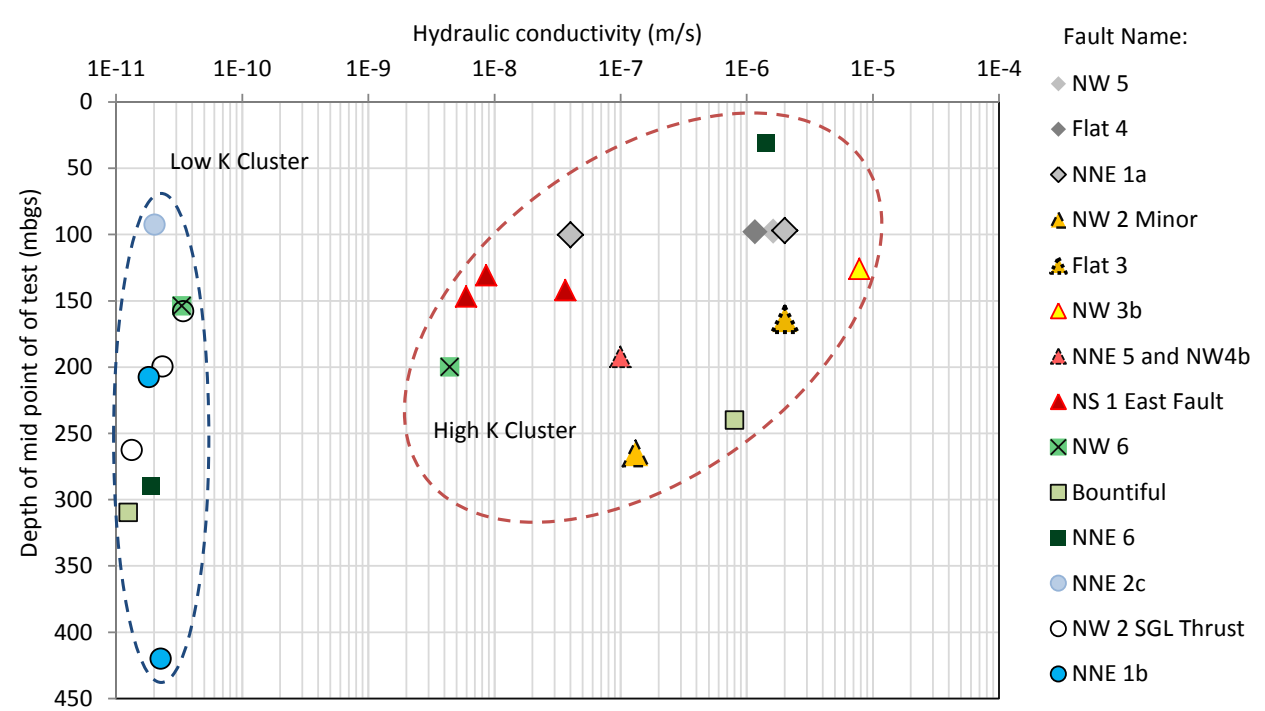

Figure 6 Hydraulic conductivity data from major structure test intervals

During development of the hydrogeological numerical model, calibration to near surface water levels in higher elevation areas was inhibited by the high conductivity of the Broken Rock; therefore, an additional factor was required to impede passive drainage, or maintain high piezometric levels within the slope. Different conceptual models were assessed in attempts to achieve calibration, including low permeability overburden cap, different anisotropy factors, changing the bulk $\mathrm{K}$ of Broken Rock and incorporating faults as barriers. It was possible that the model could only be calibrated by incorporating structures as barriers. This includes not only currently mapped and modelled structures, but also additional structures and extensions of known structures.

Discussion with the structural geology group and air photo/remote sensing interpretation supported the extension assumption, and observational data from multi-day extraction tests in the Broken Rock supported the assumption of faults as barriers. In one example, the extraction well was located a similar distance between two observation wells. The wells are located on the footwall and hangingwall of the major structure. One observation well showed rapid and significant drawdown during testing, while the other showed no effect. Based on such observations, the numerical model was calibrated assuming that faults were low conductivity barriers to flow.

As the Broken Rock domain is characterised by such high $K$, consideration of faults as conduits is not particularly relevant. Within Stick Rock domains, low $\mathrm{K}$ fault barriers are not considered significant since the Stick Rock domains themselves are also characterised by very low $\mathrm{K}$.

\subsection{Key integration mechanisms}

As per the approach outlined in Figure 1, conceptual 2D stability models were developed early in the analytical stage to assess sensitivity to various geotechnical and hydrogeological input parameters. Several phreatic surfaces, considered representative of potential pore pressure scenarios, were agreed upon between both the consultant and client and applied to the ongoing geotechnical sensitivity modelling.

Using the provided phreatic surfaces, the geotechnical workflow was advanced by incorporating the final major structures model and findings derived from bench and inter-ramp scale kinematic assessments. As laboratory data became available and parametric studies were completed on drilling and mapping data, ranges of mechanical properties were defined for the various rock mass domains. Given the large scale of the defined domains, properties were determined probabilistically so that internal domain variability could be understood more clearly. Lower percentile values were spatially checked to ensure additional subdomaining or fault identification were not required. Where probabilistic analyses were not feasible (i.e. finite element modelling), deterministic values were derived from the statistical assessments (Table 1). As the geotechnical evaluation evolved, confidence in bench and inter-ramp slope stability results improved. 
The remaining requirement needed to finalise design sectors and associated slope geometry was the final pore pressure scenarios which were being concurrently defined by the hydrogeological team.

The hydrogeology team continued to develop the semi-regional groundwater model to assess different water scenarios. The model was calibrated to available data (i.e. static and transient groundwater levels; stream flow) and provided a useful tool for estimating how the groundwater system would evolve over time and what factors were controlling pore pressure distribution. There were a number of findings from the groundwater modelling that could have influence on the stability assessment, either positive or negative including:

- Available data suggest that groundwater level variation is dominated by annual freshet. Freshet flows have more influence on the deeper, saturated zone than short high intensity precipitation events or leakage from diversion ditches.

- Recharge areas are located at high elevation, outside the area used for stability modelling.

- Calibration of the model was not possible without some structures being barriers to flow. Additional work scope was added to the major structures modelling so that faults could be extended beyond the mine boundary. The extension of the faults was required to calibrate the groundwater model.

- The Broken Rock unit may drain over time, thus the dewatering period may be shorter than previously assumed.

Water management strategies, for both inflow and pore pressure control, were assessed as part of modelling. These included scenarios for reasonable leakage and failure of water management diversions, perimeter dewatering systems and short term failure of dewatering systems (a true risk in an area prone to avalanches, potential power failures, and rain-on-snow events).

As the integrated modelling processes evolved, a number of key sensitivities were determined including:

- Broken Rock mechanical and pore pressure sensitivity: both mechanical and pore pressure sensitivity is evident within the Broken Rock domain. Rock mass parameters and thickness of the Broken Rock domain itself were found to be the main mechanical drivers affecting slope stability. The modelling also highlighted the necessity of in situ pore pressure reduction within the Broken Rock domain as well as the management of surface water influx and subsequent groundwater recharge (particularly during high precipitation and freshet periods).

- Thickness and arrangement of blast-induced damage and distressed zones: Hoek's Disturbance Factor (D) is a subjective factor used to quantify damage related to blasting and destressing (i.e. unloading). At the time of the Galore Creek study, an agreement was made to create a zonation of the $D$ parameter moving from $D=1.0$ immediately $30 \mathrm{~m}$ behind pit face to a contoured value of $\mathrm{D}=0.5$ approximately $100 \mathrm{~m}$ beyond the pit face. Although a geotechnical input, the influence of this zone on pore pressure conditions and stability was found to be important. This was proven through sensitivity analyses with and without an enhanced K 'skin' of rock at the pit face (effectively representing a depressurised zone, through free drainage or passive horizontal drains). This imparts a user-defined control on $\mathrm{K}$ of the damage zone that has to be monitored, and possibly managed. The zoning applied for the $D$ parameter has been recognized as an area for further investigation.

- Slow depressurisation in the Stick Rock Domain: the Lower Stick Rock hydrogeologic domain has a relatively low bulk hydraulic conductivity $(<1 \times 10-9 \mathrm{~m} / \mathrm{s})$. How well fractures in this unit would depressurise over time depends to a large degree on fracture connectivity, a parameter that is difficult to characterise. Assuming a low $\mathrm{K}$ equivalent porous media approach, even with low storativity, depressurisation does not extend far behind pit walls over the mine life. Stability is influenced by the modelling assumptions that control residual pore pressure, as well as assumptions about how the risk of residual pressures will be managed. 
Once final, representative 2D geotechnical cross-sections and associated rock mass and structure parameters were defined by the geotechnical team, similar sections were constructed by the hydrogeology team using FEFLOW. The cross sections did not extend to the groundwater boundaries, but were constrained based on results of the larger groundwater model to represent the conditions simulated in the regional groundwater model. Following the FEFLOW calibration, base and reasonable worst cases pore pressure scenarios were defined and resulting outputs fed into the Galore Creek stability modelling process. The scenarios selected to capture the likely range of pore pressure conditions include:

- Average freshet (base case): average freshet conditions were considered to be the likely annual worst case pore pressure conditions that could be observed. Review of historic water level data and rainfall/snow pack data suggested that large episodic rain events would not cause more unfavourable water level conditions than the freshet. This is due to the relatively long duration of the freshet over which infiltration occurs. Episodic rainfall events would cause increases in pore pressure, but not to the same extent as freshet.

- Pump failure (reasonable worst case): dewatering pump failure was considered to represent the likely worst condition at any stage of mining, but less significant at later stages when the groundwater system had drained or been dewatered.

As hydrogeological modelling advanced, active dewatering of the Broken Rock domain was confirmed as a requirement, but primarily during early mining stages. Reduction of groundwater recharge through management, which could also potentially reduce dewatering requirements, would not likely be possible. Horizontal drains in the Stick Rock are also necessary as a contingency to manage the possibility of residual pore pressure in the relatively low K Stick Rock domains.

\subsection{Integrated stability modelling}

Final stage limit equilibrium (SLIDE) and finite element $\left(\mathrm{Phase}^{2}\right)$ stability models were generated for 18 slope sections cut through the Central, West Fork, Southwest and North Junction open pits. The geotechnical team ran stability analyses using the two end member pore pressure scenarios using the updated phreatic surfaces as defined above. The phreatic surfaces were created directly in the stability software, allowing on-going adjustment of slopes and regeneration of phreatic surfaces as required.

Using these revised phreatic surfaces, the geotechnical team was able to vary the geotechnical parameters and slope geometry without issuing excessive requests to the hydrogeology team for updated full-scale model re-runs. Finite element pore pressure grids, which allowed more accurate pore pressure representation, were only used following the arrival at suitable slope geometries by the geotechnical group. The final mining scenario was imported into the full 3D groundwater model at this stage.

The Broken Rock stability was found to be favourable in both pore pressure scenarios with the exception of the Central Northwest highwall (thick (>75 m) sequence of Broken Rock and compartmentalisation) and the western wall of the Southwest Pit (reduced rock mass strength properties within the Broken Rock in this location). Slope angles required reduction beyond typical Broken Rock recommendations in these areas.

With the inclusion of a blast-induced damage zone, most modelled sections in Stick Rock were considered stable within the design criteria established through the kinematic analyses. From a hydrogeological perspective, the depressurised 'skin' was modelled by the inclusion of horizontal drains which provided a financial contingency in the event that natural depressurisation did not occur.

Of particular note, the pore pressure grids did produce variable slope toe pore pressure results relative to the initially provided phreatic surfaces. These contrasts in pore pressures required reassessment of the dimensions and parameters applied to the blast damage zone (as defined by the $D$ parameter). Following internal and external discussion, damage zone parameters were modified which reduced the impact of slope toe pore pressures to a more realistic, experience-based, degree. This is a modelling aspect that has been flagged for more detailed, possibly fully coupled 3D modelling, for the next stage of study. 


\section{$5 \quad$ Further work}

If the pore pressure compartmentalisation assumption is proven to be correct at the operating mine stage, and properly placed dewatering wells can sufficiently draw down pore pressures in isolation, an opportunity may exist to, at least locally, increase inter-ramp angles within the Broken Rock domain. This option should be re-assessed following a review of data obtained through future hydrogeological field studies or observations during operations. Regardless, pore pressure conditions will require careful monitoring and active management as the pit development progresses.

\section{Conclusions}

The integration approach presented here is simple, yet transparent and defendable. Given the common struggles with hydromechanical coupling, this approach provides both client and consultant practitioners with a realistic tool to assess the interplay between geotechnics and hydrogeology through an evolving process. Using relatively simple tools, which can be adjusted without significant time requirements, the overall stability modelling process can be efficient even with a number of controlling, complex factors.

Proper integration does not necessarily mean that all analyses have to be conducted as part of a single modelling approach. The perspective of each team is inevitably somewhat different, thus different models and tools are justifiable. The key is to identify at an early stage what the appropriate approach is and to keep the different teams from being constrained by the other; the teams need to build upon a mutual process, not dictate to each other's independent processes.

A significant key to the process shown revolves around the initial geotechnical and hydrogeological assumptions and the direction taken on the level of required hydromechanical coupling. Although, the early- and intermediate-stage sensitivity runs will help to define the key controls on domain partitioning and pore pressure distribution, assumptions will evolve as additional data become available through the analysis stage.

An improper understanding of the groundwater system places a limit on how much confidence can be placed on FEA pore pressure grids. If factors impacting pore pressure distribution, identified at an early stage through the conceptual hydrogeological model, are properly considered throughout the process, the final, more detailed, FEA-type pore pressure outputs should yield similar results to the early- and intermediate-stage phreatic surface outputs. It is recognised that in some instances the standard 2D approach discussed herein will be insufficient to appropriately characterise the risks affecting slope stability.

\section{Acknowledgement}

The authors thank GCMC for the opportunity to present this work. Specific thanks to the Galore Creek onsite staff for assistance and patience during the data collection phases of 2011 and 2012. Thanks to Jacek Scibek and Matt Clark for putting in the long modelling hours. Valuable feedback on this paper has been provided by several present and former colleagues including Michael Royle and Mark Raynor.

\section{References}

Allen, D.G. (1971) The Origin of Sheet Fractures in the Galore Creek Copper Deposits, British Columbia, Canadian Journal of Earth Sciences, Canadian Science Publishing, Ottawa, Vol. 8(6), pp. 704-711.

Itasca (2013) FLAC3D version 5.0, Fast Lagrangian Analysis of Continua in Three Dimensions, http://www.itascacg.com/flac3d/.

Read, J. and Stacey, P. (2009) Guidelines for Open Pit Slope Design, CRC Press, $510 \mathrm{p.}$

Rocscience Inc. (2013a) Phase ${ }^{2}$ version 8.0, Finite Element Analysis for Excavations and Slopes software, http://www.rocscience.com/products/3/Phase2.

Rocscience Inc. (2013b) SLIDE version 6.0, 2D Limit Equilibrium Slope Stability Analysis software, http://www.rocscience.com/ products/8/Slide.

Sullivan, T.D. (2007) Hydromechanical Coupling and Pit Slope Movements, in Proceedings International Symposium on Rock Slope Stability in Open Pit Mining and Civil Engineering (Slope07), Y. Potvin (ed), 12-14 September 2007, Perth, Western Australia, Australian Centre for Geomechanics, Perth, pp. 3-43. 
